Supporting Information for:

\title{
Mechanistic insights into the kinetic compensation effects during the gasification of Loy Yang Brown coal char in $\mathrm{O}_{2}$
}

\section{Manoj Kumar Jena ${ }^{a, b}{ }^{,}$, Vineet Kumar ${ }^{b}$, Shaomin Liu ${ }^{a}$, Chun-Zhu Li a, Hari Vuthaluru a.}

${ }^{a}$ Fuels and Energy Technology Institute, WASM - Minerals, Energy and Chemical Engineering, Curtin University, GPO Box U 1987, Perth, Western Australia 6845, Australia

${ }^{\mathrm{b}}$ Department of Chemical Engineering, Indian Institute of Technology (Indian School of Mines), Dhanbad, Jharkhand 826004, India

Corresponding author's email address: $\underline{\text { m.jena@postgrad.curtin.edu.au }}$

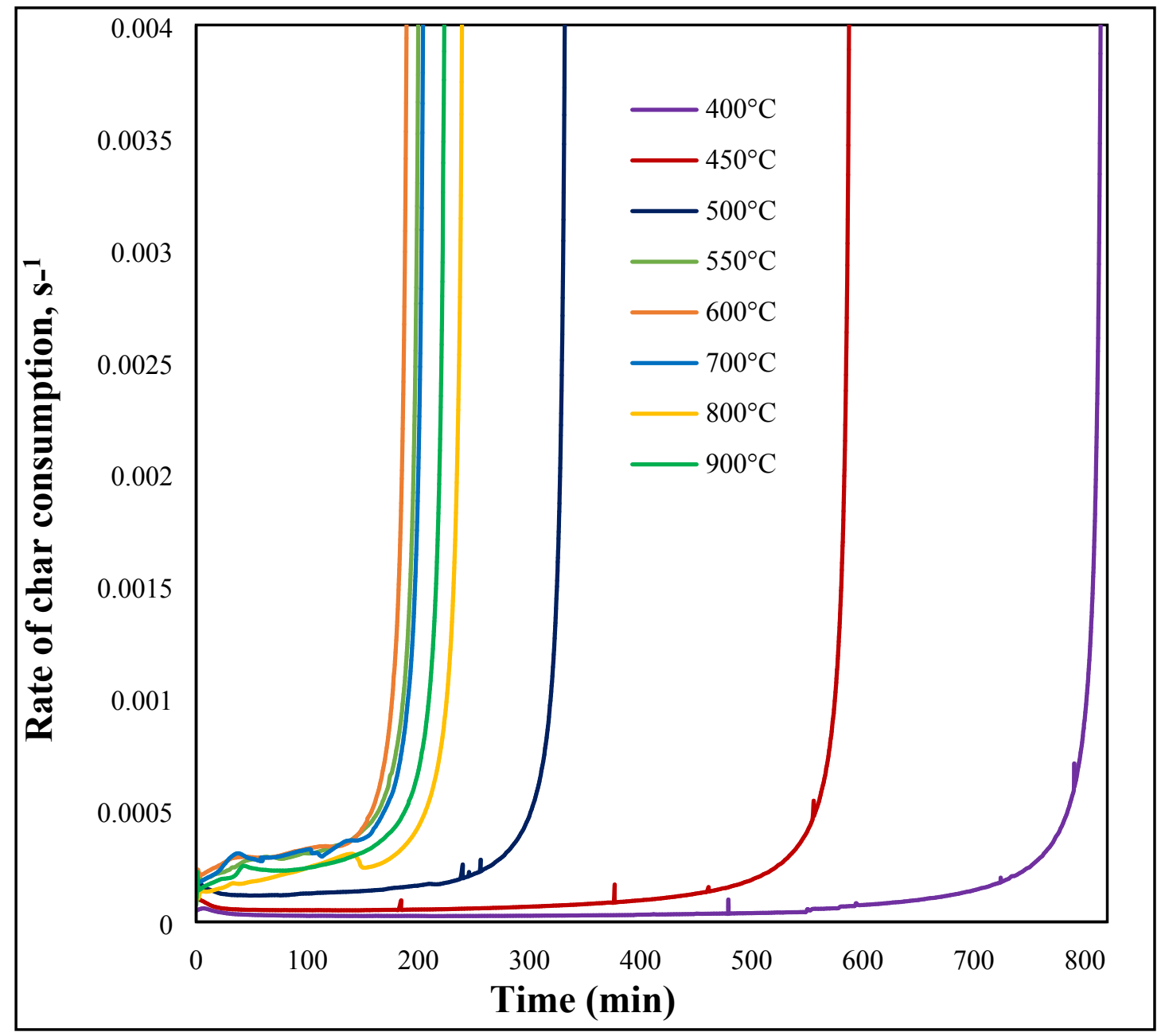

Fig.S1. Variation of char consumption rate with time for particle sizes of 106-150 $\mu \mathrm{m}$ (H-form coal) 


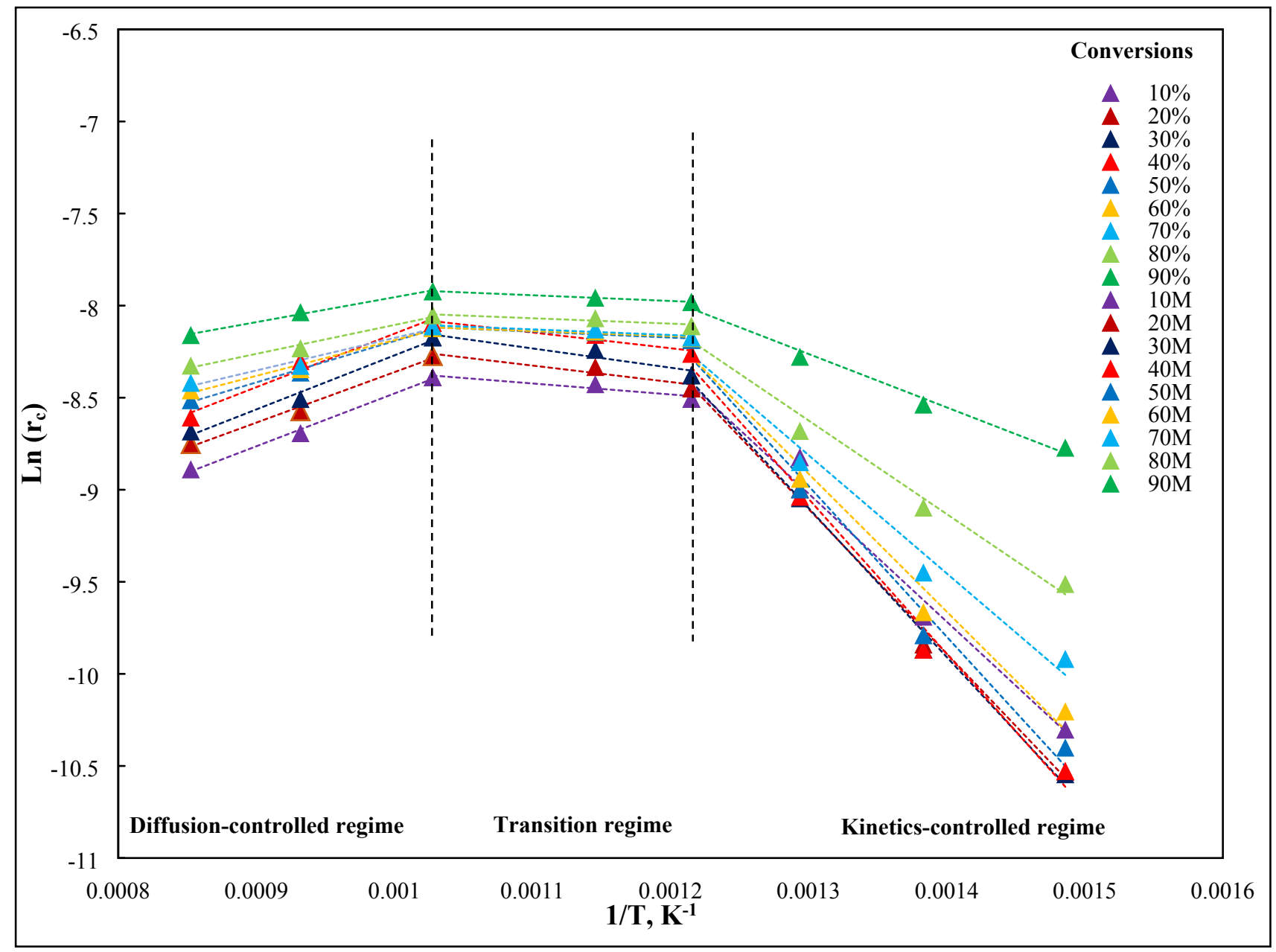

Fig.S2. Arrhenius plot of the char- $\mathrm{O}_{2}$ reaction at different char conversion levels sowing the temperature range of kinetics-controlled, mixed and diffusion-controlled regimes for particle-sized of 106-150 $\mu \mathrm{m}$ (H-form coal). 


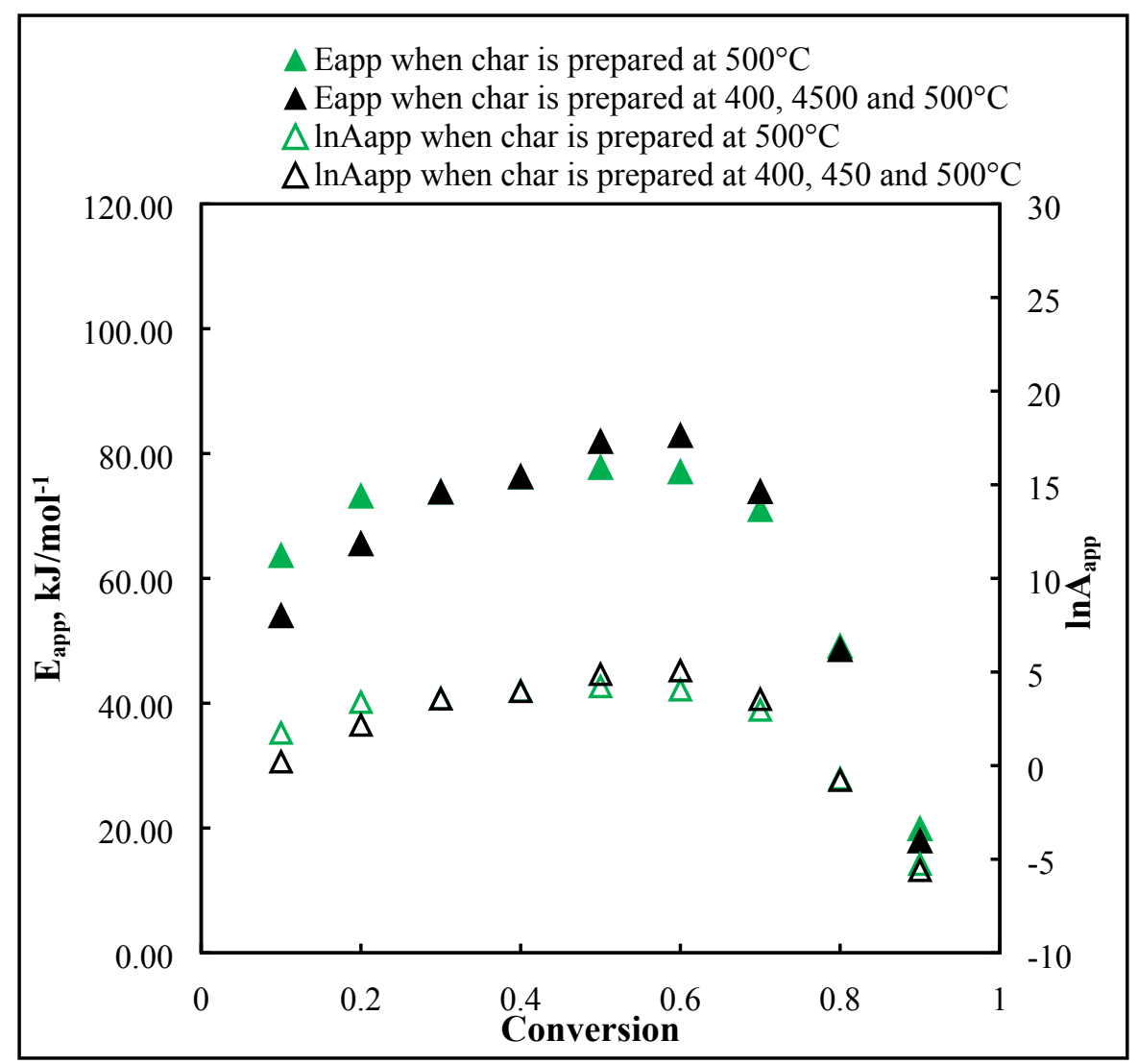

Fig.S3. Effects of pyrolysis temperature on the apparent activation energy $\left(E_{\text {app }}\right)$ and the apparent preexponential factors $\left(\ln A_{a p p}\right)$ for $106-150 \mu \mathrm{m}$ particle size. 